\title{
Code- Switching in Recent SiNdebele Literary works and how this relates to siNdebele Language enrichment or Decay
}

\author{
Lillie Beth Hadebe (Mrs.)
}

\begin{abstract}
This paper presents an analysis of both the teachers' and students' attitudes to and their conception of Ndebele/English code-switching in recent Ndebele literature. The main aim was to analyse these views and opinions in relation to language change or decay. The study was carried out in 'A' level schools and only Upper 'A' level siNdebele students were involved in this study. The sample was made up of 208 Upper 'A' level siNdebele students and 34 'A' level siNdebele teachers. A questionnaire was used to collect data from the respondents under the following themes:

- $\quad$ Language as a reflection of culture

- $\quad$ The cultural heritage approach to language

- Language growth and enrichment

- $\quad$ The cultural analysis approach to language

- $\quad$ Language decay

- $\quad$ Ndebele/English code-switching in Ndebele literature.

Some of the major findings were that both teachers and students consider that siNdebele language should reflect the culture of its speakers and therefore use of English in Ndebele literature devalues siNdebele as a language. Both teachers and students believe that literature should be written using the standard language yet the existence of the siNdebele standard language remains debatable. Recommendations for the interpretation of the code-switching in Ndebele literature have been put forward. Among them is the need to adopt a positive attitude towards siNdebele as a language that needs to grow like any other language. This does not mean an advocating for unnecessary codeswitching but using language contact to the enrichment of siNdebele language. This only comes by through critical assessment and not through blind assimilation of foreign terms.
\end{abstract}

Key terms: Code- switching, bilingualism, language growth, language decay and language change.

\section{The Imposition of English Upon isiNdebele}

In Zimbabwe, isiNdebele is spoken in Matabeleland North and South and in some parts of the Midlands region. The Ndebele people migrated into Zimbabwe in about 1837 following their leader Mzilikazi who was fleeing from the Zulu king, Shaka. From the time the Ndebele people settled in Matabeleland, isiNdebele as a language of the then conquerors was and, still is spoken as a mother tongue by most locals in this area. However, the defeat of the Ndebele by the British in 1893 led to the imposition of English as the official language of the country now called Zimbabwe. English became the new language of conquest and a new system of education was introduced so as to spread the language of the reigning masters among the defeated locals.

The education of the young in the traditional Ndebele society, as in most other African traditional societies, was encompassed in the whole life of the people. With the introduction of Western type of education, learners were isolated from the community and educated in "formal" educational institutions. Studies by Smith, in Chikombah, Johnson, Schneller and Schwille (1988), show that expatriate missionaries who developed churches, hospitals and schools were instrumental in teaching the English language to the locals. From this new perspective, English was viewed as synonymous with education. To be educated one had to learn English and an educated person was one who could speak English. It should also be pointed out that access to this new education was so limited that a considerable number of locals was left illiterate and, therefore, "uneducated".

At independence, in 1980, there was a notable quantitative expansion in the education system as observed in studies by Chikombah (1988:12). Figure 1 on page 3 indicates this great expansion.

What is of interest is that, although Zimbabwe gained independence after a bloody war against colonialism, the status of English in the education system did not change after independence. The Zimbabwe Education Act of 1987 states that English shall be the medium of instruction from Grade Four upwards. ChiShona and siNdebele are to be taught as subjects in the curriculum after Grade Three. Pupils are to be instructed in their mother tongue from Grade One to Grade Three. English still enjoys the prestige and status it enjoyed before independence. The expansion of the education system, therefore, means much wider exposure of the locals to the English language. As a result, the more educated one is, the more bilingual one becomes.

The rapid urban growth and the extensive development of industry resulted in rural-urban migration, thereby 
exposing more people to English. The use of English was imperative considering that important administrative and economic organizations were until recently largely controlled by the white settlers. It is in this light that Bolinger (1975), in Chikombah et al (ibid: 43), observes that

"... in parts of the world where conquest has imposed a language from outside, after a time the older and the newer languages may achieve a modus vivendi that is termed stable bilingualism with one language serving in one capacity and the other in another often with register distinctions."

This stable bilingualism is apparent in Zimbabwe and, as discussed earlier, most locals come into contact with English at school. Wallwark (1978) terms such speakers co-ordinate bilinguals as opposed to compound bilinguals who learn both languages almost simultaneously at home. The important consideration at the moment is that any type of bilingualism will lead to differential use of the two languages.

This differential use of languages is observed as speakers switch from one code to another to meet the demands of the topic and the situation. Interlocutors will use both languages as tools for expression and impression. Michael West, quoted by Smith in Chikombah et al (op. Cit: 145), argues that the student of English "is learning to express ideas rather than emotion; for his emotional expression he has the mother tongue." In a similar note Mkanganwi, in Myers-Scotton (1993:32), observes that the English language spoken in Zimbabwe is more of impression rather that expression. The educated local Zimbabweans are observed switching from their mother tongue to English in the presence of their educated counterparts and in most cases this is done just to impress. In some cases, however, the local Zimbabweans use English to enhance communication seeing that the education system would have tuned them to think critically using English rather than their own local languages. A language that may therefore, begin as an imposition by its conqueror speakers may, later be embraced as one of prestige and status.

For reasons advanced above, Ndebele/English code-switching remains prevalent amongst "educated" Ndebele speakers and this verifies Breiborde's statement, in Fishman (1983:5), that "the principal behaviour through which bilingualism is expressed is through code-switching" and this is the situation in some recent Ndebele novels and plays.

Ndebele/English code-switching by Ndebele authors is the issue in this research and it is arguable whether authors are not consolidating what they should eradicate.

\subsection{Statement of the Problem}

From the cultural perspective, literature has always been regarded as a storehouse of cultural values in society. This is why in literate societies, literature is taught in academic institutions to humanize and refine the minds of the learners, thereby instilling correct cultural values in them. In traditional African societies, oral literature was used to socialize the young into society. Social values were instilled through the use of songs, proverbs, folktales and legends. The culture of the people being expressed through literature and, therefore, through language makes language instrumental in promoting and reflecting the cultural and social relationships of the people. Yet language is dynamic and slowly changes to express the world view of the people at a particular time.

A trend has developed among Ndebele authors in recent times to use English conversations in Ndebele literary works. This leaves readers wondering whether this is the correct language to express Ndebele culture and Ndebele social values. If literature is a valuable storehouse for cultural values, does it, therefore, mean that the language of literature in Ndebele must necessarily incorporate English so as to express contemporary issues. Culture and Environment, a textbook published in 1933, quoted in Watson (1987:56), argues that

"... if language tends to be debased ... instead of invigorated by contemporary use, then it is to literature alone where its subtlest and finest use is preserved, that we can look with any hope of keeping in touch with our spiritual tradition."

This suggests that language in literature should always be of the standard that keeps society's social values intact. This is the cultural heritage view of looking at literature. Opposed to this conservative view of literature are Brumfit and Carter (1986:8) who argue that

"Literature is not a language variety. This can be demonstrated by pointing out that literary text is almost the only "context" where different varieties of language can be mixed and still admitted."

They further argue that legal documents would, allow no such deviation from the norms of lexis and syntax yet in literature all varieties co-exist as long as their presence is appropriate to the purpose. Does this, therefore, mean literature should accommodate code-switching as observed in recent Ndebele literature? This liberal view of literature is also confirmed and expressed by Musengezi who is opposed to the idea of chiShona literature concentrating on keeping the chiShona language pure. Musengezi, in Fiora Veit-Wild, in Riemeschneder and Schulze-Engler (1993:109), says:

"It is this opening up of the Shona language that makes it possible to explore and present the contemporary Shona world in a credible and aesthetically sound manner."

Perhaps the next question to debate is the extent of use of these varieties. One can foresee the erosion and 
decay of the base language if this opening up to all language varieties has no control. Ndebele authors may rightly argue that by using English conversations in Ndebele novels and plays, they capture the contemporary Ndebele scene but this obviously has some effect on siNdebele as a language.

The purpose of this study, therefore, is to analyse the teachers' and students' views and attitudes towards this liberal approach to literature. It is hoped that this will establish whether Ndebele/English code-switching in recent Ndebele literary works contributes to Ndebele language enrichment or to its decay.

\subsection{Research Questions}

The research questions are:

1.3.1 What does code-switching reveal about social relationships existing in a particular society?

1.3.2 What factors are viewed as leading to language change and language decay?

1.3.3 What are the attitudes of Ndebele language teachers and students towards recorded Ndebele/English code-switching in Ndebele literature?

1.3.4 How do teachers' and students' conception of code-switching in Ndebele literature relate to language change and language decay?

\subsection{The Meaning of Code-Switching As Applied To Language}

Code-switching occurs when a single speaker uses a variety of codes interchangeably within a conversation or within situations. This occurs in a bilingual or multilingual society. The individual switches from one language to another at a word, phrase or sentence level. As stated earlier in this study, will always exist where two or more languages are in intimate contact. Thus code-switching is a normal and expected phenomenon in bilingual and multilingual communities. According to Hornby (1977:3)

"To be considered bilingual, a person must have the ability to use two different languages, whereas, the term multilingual is usually reserved for individuals possessing the ability to use more than two languages"

This simple definition is adequate for general usage though it leaves a lot of issues about bilingualism not clearly explained. Researchers like Bloomfield (1933) suggest that the term bilingualism should only be applied to speakers that possess 'native like' ability in both languages whereas McNamara (1969), in Appel and Muysken (1987), suggests that an individual be considered bilingual if he can speak one language and has some knowledge of the second language. However, Ngara (1982:1) says "a person who has mastered one language and is only capable of greeting people in his second language cannot be considered bilingual". These three observations show that it is, therefore, difficult to evaluate the degree of bilingualism. If bilingualism occurs in a continuum, it becomes difficult for researchers to draw a clear line between the lowest degree and the highest degree of competence needed to qualify a speaker as bilingual or multilingual. In this research a bilingual will be considered as a person who has the ability to use two different languages, these languages being siNdebele and English. Whilst some people acquire two languages almost simultaneously at home, some acquire the second language through school teaching. In Zimbabwe, before independence, most people came into contact with English through the latter method but today, in independent Zimbabwe some children who speak siNdebele as their mother tongue are observed to speak English before the school going age. The ability to use the second language, in this research, will, therefore, entail siNdebele speakers who are able to speak, write and read English as their second language.

Studies by Appel and Muysken (1987) also show that bilingualism can either be national or individual. National bilingualism exists in three forms:

a) One language community may be in possession of two languages making everyone in the community bilingual

b) A nation may have two language communities operating via a language that is not native to both speakers. Such a situation is termed diglossia, a term originally introduced by Ferguson (1959) in such situations one language will be used at home and the other language in administration and other social functions. In a diglossic society some speakers will remain monolingual in one of the languages whilst others will be bilingual.

c) The third form of national bilingualism occurs when a society uses two different languages and one of the language groups is forced to learn the other language group's language because the latter is the dominant variety. In such cases only one group of speakers will become bilingual.

Zimbabwe as a bilingual nation can be said to display the last two forms of national bilingualism. The locals are forced to learn English in schools because English still remains the dominant variety. English is also learnt 
for communication with the outside world. This makes the speakers of siNdebele and chiShona bilingual whilst the English speakers remain monolingual. The situation in Zimbabwe can also be described as diglossic if we consider Fasold's (1984:40) definition of the term Broad Diglossia, in Chitiga (1994:7)

"Broad Diglossia is the reservation of highly valued segments of a community's linguistic repertoire (which are not the first to be learned but are learned later and more consciously, usually through formal education), for situations perceived as more formal and guarded; and the reservation of less highly valued segments (which are learned first with little or no conscious effort), of any degree of linguistic relatedness to the higher valued segments, from stylistic differences to separate languages for situations perceived as more informal and intimate."

In Zimbabwe, English is a highly valued language learnt at school and reserved for use in administrative situations. SiNdebele and chiShona remain at the low end of the situational continuum. Some local siNdebele and chiShona speakers remain monolinguals whilst the educated speakers of these languages become bilingual and capable of functioning comfortably in all social settings in which English is used. Bilingualism has been discussed in order to provide some background to the language situation in Zimbabwe. The next focus will be on the effect of bilingualism on the individual, as the individual interacts with other speakers. These effects according to Hornby (1977:7) "may vary widely depending on the particular social significance and function of the two languages." Studies have been carried out to show the effects that speaking two languages may have on one's intellectual ability and how belonging to two or more language groups might affect one's personality and identity. As code-switching is the focus of this study, the researcher will concentrate on how speaking two languages might affect code choice.

Studies by Gumperz and Hernandez, in Whiteley (1971:110), show that,

"Where speakers control and regularly employ two or more speech varieties and continue to do so over long periods of time, it is most likely that each of the two varieties will be associated with certain activities or social characteristics of

speakers."

Such speakers will be observed to switch from one code to another during conversations or situations. Valdes - Fallis, in Dubois and Crouch (1978:65), defines code-switching as "the alternating use of two languages at the word, phrase, clause or sentence level." The code-switched speech shows a clean break between the two language systems, leaving the items introduced completely unassimilated. However, studies by Myers-Scotton show that the two languages used are joined prosodically giving the whole sentence a smooth grammatical flow. The semantic and syntactic relations are joined together into a single speech act. Ndebele makes great use of noun class prefixes in accommodating foreign words. Subjectival and objectival concords are used to give the sentences a smooth grammatical flow. This can be observed in the speech below taken from Ndlovu (1989:12):

"Usecretary wakho ukuthandelani ukubuza umuntu ibizo.

Ungaze umtshele ukuthi its private uzezwa your name please."

Translation: Why does your Secretary like asking people for their names. If you say it is private, you hear her say, "your name please.

"The word, "secretary", is given a class 1a prefix 'u' and uses the possessive concord 'wa-' of that class. The English phrases, 'its private', and, "your name please", and the English word, 'secretary', although unassimilated into Ndebele, are thus joined to the whole speech act.

The concept of code-switching is generally studied when language is viewed as a process of communication. The main focus is on the individual's verbal behaviour under different conditions. According to Pride and Holmes (1972) an individual makes certain considerations when he or she decides to speak. Before the speaker chooses a code, he/she considers the receiver, the situation, the topic, the channel, the tone of the speech and the message form. The speaker uses different codes, depending on whether the receiver is a stranger or not. If the receiver is a stranger, the code used is made to fit him or her. The stranger maybe a Church Minister, a Member of Parliament, a musician or a person in any other profession. The situation may be formal or informal and the channel for communicating the message maybe in writing or oral. The tone may either be serious or jocular and the message form a prayer, a report or any other. The speaker's linguistic competence is very important in code choice. According to Appel and Muysken (1989), only speakers with sound proficiency in two or more languages will be able to use all the necessary resources of the language selected for communication.

Having chosen a code a speaker generaly code-switches from the base language to the other appropriate language. Appel and Muysken (Op. Cit) observe that this is done because code-switching serves as a referential function especially in cases where certain subjects may be more appropriately discussed in a certain language than the other. Once such topics are introduced into a conversation, codes are automatically switched to facilitate discussion. Appel and Muysken (Ibid) further show that code-switching may serve a metalinguistic function. This time switching is used for prestige or merely to impress the other participants. A good example is the way Ndebele speakers code-switch between Ndebele and Zulu after being in South Africa, just to display their linguistic skills in Zulu and to impress their interlocutors. Code-switching has also been used to serve a poetic function. Creative poets 
use puns, jokes, and rhymes across languages to bring out their themes. Ngugi, in Petals of Blood, uses Swahili and Gikuyu words in between his narrative and descriptive passages. This has, however, been criticized in some quarters by people who feel that the use of such words reduces readability, hinders communication and irritates non-Swahili or non-Gikuyu speakers. In the same novel by Ngugi there is a song sung in Swahili by Munira. Whilst this song is sung during the height of a crisis, its impact to a non-Swahili speaker is lost because he/she is unlikely to understand it. Therefore, whilst the use of two or more languages in creative work displays creativity on the part of the author, perhaps such words or passages have to be translated into the base language for the benefit of all readers.

Researchers have found out that code-switching is of different types. Consider the following sentences recorded by Ndlovu(1983:51)

"Mfayabo: Kulula mfana, its very simple !

Khangela uFelokwakhe ngizamtshela ukuthi kumele

mina laye sibe engaged in secret ukuze simangalise

abangane bakhe kanye labanye abantu. Ngiyakwazi

kuthi kuzamthokozisa lokho. Uyabona, she is in need of

a morale boost. Angithi uzazi aliwe ngu Mkhunjulwa wakhe ?

Nyamayabo: Uthini wena? UMkhunjuiwa usemalile okwanini Mfa ?

Mfayabo: Kulobuchopho obukhaliphileyo kulelikhanda mfana. I have

an analytic mind...."

Translation:

Mfayabo: It's easy, my boy, it's very simple! look, I will tell Felokwakhe that we have to be engaged in secret so as to surprise her friends and everybody else. I know that will please her. You see, she is in need of a morale boost.Isn't it that she considers she has been rejected by Mkhunjulwa.

Nyamayabo: What are you saying? When did Mkhunjulwa stop loving her, Mfa?

Mfayabo: $\quad$ I have brains boy. I have an analytic mind.........

The topic, the speakers and the setting have not changed yet the speakers switch codes. The alternation is not really recessary to bring out the meaning of the passage yet it is used. Such use, according to Gumperz and Hermandez, in Whiteley (1971:112), may merely be a matter of the "individuals momentary inclination" to a particular language. The use occurs because of language contact. Appel and Muysken (Op. Cit) refer to this switching as 'intra-sentential' while Hudson (1980) refers to it as 'conversational' code-switching. Codes are switched within a single sentence and this is at times referred to as code-mixing.

Basically there are two major types of code-switching. The two types of code-switching are metaphonical code-switching and situational code-switching. Bloom and Gumperz in Hudson (1980:56) define metaphonical code-switching occuring;

"where a variety normally used only in one kind of situationis used in a different kind because the topic is the sort which would normally arise in the first kind of situation."

A change in topic leads to a change in the code because the speaker feels comfortable explaining one topic in a different code than the one previously used. The change in code adds some distinct flavour to the topics discussed as a full explanation is likely to be given. A teacher might switch codes metaphonically to explain certain concepts. In Ndlovu (1989:12) Thamsanqa, a bank manager switches to English to give his sister-in-law Nontokozo a brief explanation of inflation.

Thamsanqa:......Umuntu uthi esuka ebhanga engenangene ezitolo,

lemahofisini athenge lapha, abhadale amaaccounts. Lithi lisiyatshona esesidla inqwenqwe zomlomo, kudala ihambe lomoya imali ayikhokhe ebhanga ekuseni. Yiyo iinflation leyo Nonto.....The value of our dollar has been eroded and the prices have escalated hence the high cost of living, Nonto.

\section{Translation}

Thamsanqa:....After one has been to the bank he/she enters into stores and offices to pay accounts. By the end of the day all the money will be gone living one a hungry man/woman. That's inflation, Nonto.....The value of our dollar has been eroded and the prices have escalated hence the high cost of living, Nonto.

Studies by Wardhaugh (1986: 102) show that situational code-switching occurs "when the languages used change according to the situations in which conversants find themselves." Interlocutors will use one language in one situation and another in a different one. The speaker changes from one code to the other as situations arise. Codeswitching has, however been challenged in some circles, especially considering that each language is well equipped to express the culture of its people. According to Whorf, in Kess (1975:36) 
"Each culture and each language was to be considered as an entity unto itself and described in exactly those terms without any

Unnecessary outside reference and each was considered as being an ideal language or culture for that particular environment and worldview."

Whereas one can agree that code-switching is inevitable in a bilingual or multilingual society and is at times used to explain certain concepts to a great advantage to the listener, the question one asks is whether it is really necessary, especially considering that every language has the potential to express its world view. Where limitations in lexis exist, words have been loaned from other languages to fill the gaps.

Asked why they use Spanish in an English sentence or vice versa the Spanish interviewed by Gumperz and Hermandez, in Whiteley (Op Cit: 117) give the following explanation.

"If there's a word I can't find, it keeps coming out in Spanish.

I know what word I want and finally when I.......well I bring it out in Spanish, and I know the person understands me."

Spanish is being used in this case because some topics or items of experience are more easily recalled in one language than in the other, therefore, causing the speaker to switch codes. Littlewood (1989) observes that switching is part of the communication strategies which speakers have been observed to use. When speakers fail to communicate they can avoid communication, adjust the message, create new words or switch on to another language. Important to note is that code-switching occurs when the speaker resorts to it for social or cognitive reasons.

At times code-switching is used for reasons of confidentiality and secrecy. In such instances, a language not known to the other speakers is used so as to cut some participants. Fishman (1984) observes that speakers will attempt to use speech patterns that are characteristic of their recipients. This is done for social approval or to gain a high level of communication efficiency. Some psycholinguists explain code-switching by appealing to some theories of second language learning. Such theories include the inter -language theory, a term coined by Selinker (1969), in McLaughlin (1987:60), to mean "the interim grammars constructed by second language learners on their way to the target language". As speakers learn a second language, an inter-language is developed. This interlanguage, however, ceases to develop when, fossilization occurs. According to McLaughlin (Ibid: 61) fossilization is the state when an individual "ceases to elaborate the interlanguage in some respect, no matter how long there is exposure, new data or new teaching". In an attempt to communicate in the second language the speaker faced with problems, switches to the native language. It is in this light that Tarone (1983) in McLaughlin (Ibid), writes of a capability continuum. Tarone observes that individual speakers either possess a stable subordinate style or a super ordinate style. The stable subordinate style is virtually free of the first language influence whereas the super ordinate style shows influences of the first language. Of interest, however, is that code-switching also occurs when speakers are using their native language as a base language, as is the case in this study. Perhaps switching from the second language to the native language when the inter language fails to meet the demands of the conversation is easier to explain than switching from the first to the second language. One obviously fore-sees a stage when extensive switching may have some effects on the base language. An example is that code-switching has an effect of pidginizing a language. A pidgin is a form of speech variety created from two languages to facilitate communication amongst speakers of these language groups. The effects of code-switching on the base language will be discussed in the second part of this chapter which deals with language as an instrument of socialization and communication and also examines language change in greater detail.

\subsection{Language as a Changing Instrument of Socialization and Communication.}

This paragraph focuses on language as a means of socialization and communication. The paragraph also discusses the dynamism of language. Because language changes it can never be 'pure' in the sense in which some people think it should cease to grow.

\subsubsection{Language as an Instrument of Socialization}

Language acquisition is part of the socialization process. Krashen (1985), in McLaughlin (1987:20), describes acquisition as a subconscious process of acquiring a language. Trudgil and Anderson (1990:43) describe socialization as a "process by which a biological being (new born baby) is transformed into a social being". Language plays an instrumental role in making a human a social being. Language is part of culture. It expresses and transmits culture. Knowing one's native language enables one to become a member of one's society. Language, therefore, unifies its speakers, binding them together in a common bond and providing a common symbol of identify. As explained by Chomsky, in his studies of language acquisition, native speakers master the rules of their language subconsciously. The language rules are not taught to the native speaker yet by the age of five the speaker masters them and is able to construct and understand an infinite number of sentences. It can thus be argued that all speakers of a language carry models of what is good and correct language. This leads us to the idea of the standard language. 


\subsubsection{Standard Language and Status}

We start this part by asking the following question: "Which language variety is the standard variety?" This is a difficult question to answer yet people will aver that there is something called standard language which is used as a yardstick by which other language varieties can be judged. This standard language is also associated with sound social and cultural values. As children come into the school system, they are often reminded to mind their choice of words, the idea being that non-standard language, if ever it exists, is associated with low social status and perhaps, also with lack of culture.

In modern literate societies, the standard language is associated with written language. Stringer (1973:41) says: "Written language may be valued more highly than everyday Colloquial speech partly because a written language usually Serves as the standard language and partly because it is associated With artefacts of high culture such as literature."

Literature is, in this case, associated with high culture while everyday "colloquial" language is generally not. But is this true? Before written language came into use, societies transmitted culture through the oral word or by merely handing over artefacts from one generation to another. Since the invention of writing, written records of culture are passed on from generation to generation over barriers of time and location. Literature is thus taught in schools so as to promote this cultural heritage. However, be it written or spoken, language remains a social act deeply rooted in the social life of the people. As speakers interact, they develop a language that explains their existence at a particular point in time. If this is the case, then it is difficult to imagine the existence of a 'pure' language. The question of purity of language, in general, and of Ndebele, in particular, needs elaboration.

\subsubsection{Arguments For and Against Language Purity}

It has been observed that self-appointed guardians of purity and virtue exist in any language situation. The prime concern of these people is to keep their language pure and to guard against language adulteration and conserve their language through generations. These people will, therefore, raise their heads whenever they consider that their language is being polluted. Discussing the impossibility of conservatism and purism in the Arabic speaking world, Dorian, in Bright (1994:479) says:

"The grammar books teach a lot which long ago ceased to be of any relevance to standard Arabic as it is practised today....Since the rules of Arabic grammar are based on prescriptive rules instead of actual usage. They will remain hopeless and unattainable goals for the vast majority of Arab learners."

In the name of purity, language learning in learning situations similar to the one described above, becomes a content subject instead of being a social act because learners and the subject operate at different social times. Language, according to Dorian, has to be current and reflect the present times. Dorian argues that this does not mean that language should be made so relevant to the new nation that it risks alienation of the language from everybody else except the elite.

In 1996, in The Chronicle, there have been arguments about the type of Ndebele spoken today and its place in society. Among the debaters, have been guardians of language purity and critical analysts of language.

Modise, in an article entitled, "Save our language", The Chronicle, February 8, 1996, expresses his concern over speakers he considers use a corrupted Ndebele language. He advocates a return to what he calls the original Ndebele once spoken in Natal. Such speakers, according to Modise, eventually destroy Ndebele language. In answer to someone who had previously advised Ndebele speakers to read Ndebele literature so as to keep the language intact, Modise says:

"You ask me to read Ndebele literature. There are people who are involved in destroying our language, who are also busy writing books and distorted literature which they call Ndebele."

Modise is not convinced that the present Ndebele literature is good enough for human consumption. He actually describes it as 'distorted' to express the extent to which the language has deviated from the norm.

OkaMbungwana, in a letter to the editor, The Chronicle, February 22, 1996, advises Ndebele speakers to read Zulu literature, suggesting that Zulu literature offers the standard language needed by Ndebele speakers if they are to save their language.

OkaMbungwana argues that "We do not have a desire to hear our rich language being adulterated with cheap and distorting words and terms, yet this is rife these days. It is our duty as speakers of the Ndebele language to enrich and nurture it."

According to Oka Mbungwana, this enriching and nurturing involves reading Zulu language and literature. The question is whether the language brought by the Ndebele from Zululand and planted in Matabeleland could ever remain static. In the same way, the Zulu language spoken in Zululand today can not be expected to be the same Zulu spoken in Zululand a hundred years ago. Zulu obviously has influences from Sotho, Swati, Xhosa and Africaans in the same way Ndebele has influences from English, Kalanga, Shona and some languages found in Zimbabwe.

In his contribution to the debate, Sibanda, in a letter entitled, "Ndebele is not Zulu" The Chronicle, February 
16, 1996, appeals to Modise not only to read his books but also to analyse his facts. Sibanda is against Modise's suggestion that people should read Zulu authors like Nyembezi. To Sibanda this serves no purpose because Nyembezi writes in Zulu and not in Ndebele. Sibanda also argues that over 80 per cent of Ndebele speakers are not of Nguni origin or people who are originally from Zululand but mainly people who the Nguni found in present day Zimbabwe. This suggests that the present day Ndebele speakers are the makers of their language and so should be left to do so.

In support of this argument is Tunu, The Chronicle March 2, 1996, who quotes Professor Canaan Banana: "For religion to succeed in any country it must be like a river whose water changes colour once it reaches a certain type of soil: red soil, red water and black for black."

It is a historical fact that Ndebele is rooted in Zulu but the language that is spoken by people in Zimbabwe is Ndebele not Zulu. Tunu reminds Modise that the Ndebele of today are made up of Sothos, Swazis Tswanas and many other people and that Ndebele and Zulu will never be the same since the languages are conditioned by social interaction of peoples. Like water running in different soils, the two languages have changed to suit the social existence of their speakers.

Sigogo, a well known Ndebele novelist and poet, in a letter to the editor, The Chronicle, March 2, 1996, bemoans the idea of purity in Ndebele and points out that the words considered not to be Ndebele are actually Ndebele because the Ndebele speakers use them. He attacks people who are "over turning our desks and spilling our ink, accusing us of destroying and distorting Ndebele literature." Although Sigogo is not correct in suggesting that literature, in Ndebele, was non-existent before Ndebele authors started writing it in the late 1950's, the main point of his argument that the authors cannot be accussed of 'profaning' the Ndebele language by using expressions not once used in Zulu, is valid. He reveals that Ndebele authors meet every month to discuss how to improve Ndebele literature. It would, therefore, be insane for these very people to destroy their own building. In conclusion Sigogo bluntly scorns these accusations by sarcastically and ironically stating:

"At the same time may the gods of Ndebele literature,baptize and bless the purists for unadulterated literature yet to be produced in holy Ndebele."

Nondo, in a letter entitled; 'Dynamism of language,' The Chronicle, March 16, 1996, writes in answer to all the previous arguments about Ndebele. His first correction is that the language is Sindebele and not Ndebele as previously suggested. According to Nondo, the fact that Ndebele is deeply rooted in Zulu is a known fact and as such there is no need to belabour the point. He urges Ndebele language speakers to accept that Ndebele is dynamic like any language and, therefore, is slowly growing everyday.

"The dynamism of a language, if it is to stay alive and worthwhile has to absorb into its vocabulary what it does not have. The new concept is assimilated according to the phonological and grammatical structures of that language. Sindebele does that, a good sign that the language is growing."

Language growth, however, does not mean that every new word will be accepted into the base language. Nondo suggests that there is a certain amount of rejection. This rejection protects the language from being adulterated until it collapses. These selectors and rejecters of new words should be sufficiently aware of the workings of the language to make critical analyses of it in relation to other languages. Nondo, therefore, does not advocate for blind assimilation of words but for meaningful assimilation because dynamism is good for the language and does not necessarily lead to its weakening.

The fact to be realized by all language speakers is that language changes as years go by whether we like it or not. In some cases this language change may lead to total language shift while in other cases it may lead to language enrichment. Giles, Bourhis and Taylor, in Appel and Mysken(1987:33) suggest that language change depends on the "ethno linguistic vitality". This ethno linguistic vitality is a combination of status, demographic and institutional support. They argue that in communities with high vitality, language is maintained or better still shifted towards extended use. Low vitality will lead to a complete shift away from the native language towards the dominant or prestigious variety.

Studies by Giles et al (ibid) show that language change is a result of the following: economic status, modernization, industrialization, urbanization, social status, sociohistoric status and language status. Where speakers command low economic status, there is a strong tendency to move towards the dominant language. According to Giles et al (ibid) speakers of Spanish in the United States of America, because of their low economic status, regard Spanish as the language of poor people. English is associated with academic achievement and economic progress. As a result, this has negatively affected Spanish as a language in America as its speakers strive to learn English. During times of modernization, industrialization and urbanization minority languages suffer because they are considered as languages of poor, old fashioned people who are traditional and, therefore, fail to cope with the reality of modern life. In cases where linguistic diversity exists due to urbanization, a dominant language may be promoted as an urban lingua franca. Cooper, in Bender (1976), illustrates how in Ethiopia, Amharic, was promoted and spread into the surrounding country - side through being used as an urban lingua-franca. Due to the increase in urban population in Ethiopia, as in the case in most African cities, linguistic diversity was created because the migrants 
came from different language groups. Amharic was then used as a language of communication causing it to spread into the country side.

However, on a much positive note, rural groups have been found to preserve their language much longer than their urban counterparts. Studies by Anderson (1979) show that the Ukraniam groups and other ethnic groups, in Saskatchewan, living on farms have preserved their language better than those in small towns who easily succumb to linguistic pressure.

Social status is largely dependent upon economic status. Language groups with a low self esteem tend to shift towards languages associated with higher social status. Bolinger, in Chikombah et al (1989:146), observes that: "Where a community is looked down upon, its speech is likewise, and the speakers themselves may accept the devaluation and try to exchange their old ways for new."

In Zimbabwe, local languages were looked down upon during the colonial era and the speakers seem to have accepted the devaluation of their own languages. The social status of a group gives its language a certain language status. Owing to its higher social status accepted by many Zimbabweans, English continues to be accorded a higher language status from other languages. Perhaps Zimbabweans feel that the situation cannot be challenged seeing that English, like French, Russian and Spanish command high statuses because they are languages of international communication.

Some factors like the mass media can also lead to language shift or language maintenance. If broadcasting is done in minority languages, this might boost these languages unlike when all broadcasting and publications are done in the dominant language alone. The number of domains where a language is used either decreases or increases its value. Studies by Hill and Hill (1977), in Appel and Muysken (op.cit) show that in cases where all administrative and governmental services use one dominant language, the usefulness of the subordinate languages diminishes, causing the speakers, especially the young to be demotivated towards their languages. Education, as discussed earlier in this dissertation can either promote or demote language growth. If children are taught in their native language even if it is a minority language, maintenance of that particular language is achieved.

From the arguments above, it can be noted that certain factors, if not closely guarded, can result in serious language shift, causing the language to decay. However, the important point to note is that as society experiences social, technological and political changes, languages are also influenced by these changes. Some words are lost while others are gained. Others still change their meanings or gain additional meanings. All this is natural and, in most cases, occurs unnoticed through social interaction. Once speakers realise that certain words no longer capture certain meanings, new words are adopted or old ones lodged with the new emotional force needed. This is not done in isolation by individuals but by all speakers as a way of developing alternative ways of exploring their reality for social and technological progress. Language change can therefore, not be associated with language decay but with progress and development.

\subsubsection{Focus on Code Switching}

At this juncture, let us focus on code-switching in relation to language change. Perhaps we can compare code-switching to slang. Slang is informal and very often fashionable but temporary. People use slang to make their speeches colourful, current and interesting. This is often done during certain ages in life. As time goes on speakers cease to bother about being current and fashionable. Slang thus filters off the language quietly just as it came in. Some slang words, however, are silently adapted to the language. This is done through a social process by the members of a speech community. Similarly code-switching remains temporary and filters off the base language. Zimbabweans today argue that code-switching is leading to a loss of cultural identify and a shift in social values. The younger group are motivated towards the English culture at the expense of their 'Ndebeleness'. The question is whether this change in social values is due to code-switching or to their attitude towards the mother languages. It is unfortunate that language Policy in Zimbabwe has not helped Zimbabweans to shed off the inferiority complex planted in them by the Colonial Masters. What speakers should realize is that no language is more logical or potent than others. Every language, be it Ndebele, Shona or English is highly and equally competent. Our local languages have the potential to fully explain reality at any given time. Using our languages in critical thinking will, therefore, sharpen our languages to meet the technological advancements of the century and this can only come by if the Zimbabwean Language Policy permits. Once our languages are valued highly and used in critical thinking, literature will definitely capture that high level of social interaction. This will lead to greater confidence and more positive attitudes towards their use." Language is part of society and so it should be allowed to develop in step with societal advancement. Language change is not a sign of decay but a valuable phenomenon in language development. Our languages need not be protected against it.

\subsection{Research methodology}

The purpose of this study was to understand both teachers' and student's views, and attitudes towards the use of English expressions Ndebele literature. The main assumption is that the teachers' and students' attitudes towards 
their local languages influence their views and attitudes towards code-switched conversations in literature. The findings will be assessed in relation to the following themes.

- $\quad$ Code-switching in literature.

- $\quad$ The cultural heritage approach to language.

- $\quad$ The cultural analysis approach to language.

- $\quad$ Language growth and enrichment.

- $\quad$ Language decay.

- $\quad$ Opinions on the present Zimbabwe language policy.

- $\quad$ Language as a reflection of culture.

This study was carried out in the Matabeleland North, Bulawayo Metropolitan and Matabeleland South Regions. These regions lie in the South and South Western parts of Zimbabwe. The study was centred in these three regions because they are predominantly Ndebele speaking. Virtually all secondary schools in these regions offer Ndebele at 'O' level and some of them offer it at 'A' level. In 1996, when this study was carried out, Matabeleland North and South had a total of thirty 'A' level schools. There were twenty 'A' level school in Matabeleland North and there were ten 'A' level schools in Matabeleland South. These schools can be divided into Mission schools, Government schools and Private schools. The focus of this study was on the population of these schools offering Ndebele at A' level.

For the purpose of this study, a sample of 66 percent of the A' level schools was selected. 66 percent of the schools was considered representative enough of all the schools to yield valid results. These schools were divided into subgroups as the researcher considered that the location of each school and its school type would have an influence on the student's attitudes towards languages. Best and Kahn (1993:17) observe: "At times it is advisable to subdivide the population into smaller homogeneous groups to get more accurate representation." Stratified random sampling was, therefore, used so as to get an equal representation from each subgroup, thus avoiding a biased sample.

The schools were sub grouped into five categories: mission schools (8), rural government schools (4), urban former group A government schools (9), urban former group B government schools (5), and private schools (4).

Owing to the factors discussed above and the effect these factors might have on subjects in the various schools' the sample was, therefore, stratified as shown in the Table 1 below.

Table 1: Stratified Random Sampling Plan of the School Population

\begin{tabular}{||l||l|c||}
\hline \multicolumn{1}{||l||}{} & $\begin{array}{l}\text { No. in } \\
\text { Grp }\end{array}$ & No. in sample 66\% of (n) \\
\hline Mission Schools & & 5 \\
Rural Government Schools & 8 & 3 \\
Urban Former Group A Government Schools & 4 & 6 \\
Urban Former Group B Government Schools & 9 & 3 \\
Private Schools & 5 & 3 \\
& & \\
& & \\
\hline TOTAL & & 20 \\
\hline
\end{tabular}

Simple random sampling was done. In this way twenty schools were selected. It was from these twenty schools that the subjects were selected.

For the purpose of this study, students in the Upper "A' level were selected. From each school in the sample 50 percent of the total population of students studying Ndebele at Upper A' level were selected through systematic sampling as follows; one name was picked from the first two names and thereafter every second name was picked until a sample of 50 percent of the population was selected. In cases where there were both female and male students, the students were not grouped according to gender as the researcher considered gender not to be a significant variable thestudy.

There were two teachers teaching 'A' level Ndebele at each school, with one teaching the lower 'A' level and the other the Upper 'A' level classes. For this reason, no sampling was done but the total population of all 'A' level Ndebele teachers from all sampled schools was considered for the study. 
In order to obtain and assess the selected teachers' and students' attitudes towards, and their conception of Ndebele/English code-switching, a twenty-five item questionnaire for both teachers and students was used. The questionnaire took the form of the Likert attitudinal scale. A thematic approach to designing a questionnaire was followed. This was done so as to ensure that each item sampled a significant aspect of the study, thereby attaining item validity. The questionnaire was designed to tap information on the following themes:

- $\quad$ Opinion and views on Ndebele/English code-switching recorded in Ndebele literary works.

- Views on cultural approach to language.

- Views on the cultural analysis approach to language.

- $\quad$ Language growth and enrichment.

- $\quad$ Language decay.

- Opinions on the present Zimbabwean Language Policy.

- $\quad$ Language as a reflection of culture.

Of the 36 teacher questionnaires sent out, 34 were returned. Of the 243 questionnaires sent to the students 208 were returned.

\subsection{Research Findings}

The research findings, in some cases confirmed the researcher's assumptions. In other cases they revealed information and views the researcher had not expected. The major findings were:

1.7.1 That both teachers and students considered that Ndebele language should reflect the culture of its speakers. 1.7.2 That among both teachers and students there were people who believed that cultural imperialism was promoted through language. The outcome confirmed the researcher's assumption that by learning English, the locals did not only learn to communicate in English but learnt the culture of the English people as well. In fact all languages transmit culture. Hence code switching would mean that English culture is filtered into the Ndebele reader through siNdebele texts.

1.7.3 That literature should be written using the standard language.

1.7.4 That most of the teachers and students believed that siNdebele should be strictly protected from foreign language infection. As a result the majority of both teachers and student believed that the use of English in Ndebele literature adversely influenced Ndebele culture and its social values. Introducing English into Ndebele literature means introducing English culture into the Ndebele culture.

1.7.5 That using English in Ndebele literature reduces communication. The English brings new images unto Ndebele and, perhaps, conditions Ndebele readers to see the world in certain ways that are obviously foreign to them, thereby reducing communication between writers and the readers. This is inevitable whenever two languages meet. 1.7.6 That the existence of the standard Ndebele language remains debatable. The debate rages whether it is possible to identify a prestigious variety of Ndebele which should be labelled "standard Ndebele".

1.7.7 That teachers considered formality and purity in written language as less important in characterization while students maintained that formality and purity is important even in characterization.

1.7.8 That teachers considered that both language contact and analysis of a language in its different varieties are a powerful means of language growth. The findings confirmed the assumption that puristic and conservative attitudes may, at times, be a threat to the dynamism of any language. Whilst teachers were of the opinion that interaction with other languages is a powerful means of language growth, the majority of the students objected to this. Really if language has to grow and be able to explain social advancement of the present century, it needs to make use of selected terms borrowed from other language with which it is in contact. To refuse to borrow these terms and protect the language from all foreign infection may adversely affect it and retard its growth. However borrowing of words has always been accepted and borrowing the whole sentences or phrases ushers in a new language phenomena which could erode the base language.

1.7.9 That the issue whether language changes means language decay remains unresolved. It is to be recalled that language change does not necessarily mean a blind assimilation of new facts and ideas as stated by Nondo, The Chronicle (Op.Cit:5). Language change requires a critical analysis of facts speakers, linguistically aware of the workings of both languages. Some terms from foreign languages filter in and out of the language while others filter in and stay as what happens in the case of slang words. Code switching was thus leading to language decay. There was fear that formalizing code switching in literature would eventually weaken the base language.

1.7.10 That the majority of both teachers and students considered that there were certain socio-economic and technological concepts that Ndebele could not express.

1.7.11 that the majority of the teachers and students believed that Ndebele could not replace English as a medium of instruction in the Zimbabwean Education system. It may be recalled that the Zimbabwean language policy states that English shall be the medium of instruction from Grade 4 upwards while local languages are taught as subjects 
from this level. Having local languages become medium of instruction, would not necessarily mean an omission of English from the school curriculum. English would remain a subject in the school curriculum just as the local languages are today. The majority of respondents agreed that all languages have the potential to grow yet the same respondents lack confidence that Ndebele is capable of handling some concepts.

\subsection{Recommendations}

From the findings and conclusions of this study flow the following recommendations:

1.8.1 All languages have the potential to grow and meet the social needs of their speakers. There is an urgent need for the adoption of positive attitudes by Ndebele language speakers if the language has to move away from being a content subject, storing traditional culture, into a living language that will express the current existence of its speakers. Writers of local languages should strive towards meeting this goal through making their actors to communicate all issues using the base language.

1.8.2 The pidginizing of siNdebele is not the aim but the aim is to have a language that will move in step with the development of the time hence willy- nilly of codes in literary works should not be allowed.

1.8.3 Finally it is recommended that the root causes of code-switching in literature today be studied further so as to establish its functions and implications. It has been realized in this study that respondents were not confident about the growth of Ndebele as a language. To them English remains the prestigious language that can explain all socio-economic and technological concepts of the century. Whilst this is true, the researcher recommends that our local languages be given the chance to grow as well. This can only happen if the language policy permits. Ngara (Op.cit:28) recommends that the child's mother- tongue : siNdebele, chiShona and English be used as a medium of instruction at the primary school level and that English be the medium of instruction at secondary and higher levels of education. The basic aim is to help local speakers develop positive attitudes towards their languages; attitudes that will make the speakers positively make use of their contact with other languages.

It is, therefore, hoped that this research will shed some light on the effects of English on local Zimbabwean languages, especially, code-switching in literature and will prompt educationists and language planners to make further investigations into the Zimbabwean language Policy.

\section{References}

[1]. $\quad$ Appel, R \& Muyseen, P (1987): Language Contact and Bilingualism.Singapore : Colsett Private Ltd

[2]. $\quad$ Bender, M.E. (Ed) (1976): The Non-SemiticLanguages of EthiopiaU.S.A: Michigan State University

[3]. Best, J.W. \& Kahn, J.V (1993): Research in EducationU.S.A: Simon \& Schulste IncBorg, W \& Gail, M.D (1979):EducationaResearchLondon: LongmanBreitborde, L.B. (1983): Levels of Analysis in Sociolinguistic explanation: BilingualCode - switching, social relations and Domain theory", in J. Fishman, (Ed), International Journal of the SociologyOf Language. Volume

[4]. New York: Maiton Publishers Brumfit, G.J \& Carter, R.A. (Ed, (1986) :Literature and Language Teaching.

[5]. Hong Kong: Hope Services

[6]. Chitiga, M. (1994) Code-Switching in the Classroom. M.A. Dissertation Harare: University of Zimbabwe

[7]. Chikombah, C. (1988): Education Issues In Zimbabwe since Independence Stockholm

[8]. Chikombah, C, Johnson, E. Scheller, A. And Schwille, J (1988): Education in New Zimbabwe. Michigan State UniversityDorian, M.C (1994): Purism vs. Compromise in Language revitalization and language revival", in W Bright (Ed) : Language in Society. Vol 23 No 4Cambridge University Press.

[9]. Fishman, J. (1984): "The Dynamics of Speech Accommodation", in J. Fisherman (Ed): International Journal of the Sociology of language: Vol 46 New York Marton Publishers

[10]. Herbert R. K. (Ed) (1992): Language and Society in Africa The Theory and Practice of Sociolinguistics.Cape Town: Creda Press Pvt Ltd

[11]. Hudson, R.A (1980) : Sociolinguistics Great Britain: Cambridge University Press Kess, J F (1976): Psycholinguistics London: Academic

[12]. Littlewood, W (1989): Foreign and Second Language Learning. Language Acquisition research and its Implications for the classroom. Singapore: Colsett Private Ltd

Modise, T. (1996 February 8): "Save our Language", Letter to the Editor The Chronicle p.5

[14]. Myers - Scotton, C. (1993): Social Motivations for Code Switching Oxford: Clarendon Press

[15]. Ndlovu, T. P. (1983): UMkhunjulwa ufelokwakhe

[16]. Gweru Mambo Press.

[17]. Ndlovu, T.P. (1989): Uchithwa NgowakhoGweru Mambo PressNgara - E.A. (1982): Bilingualism, Language Contract and Planning. Proposal for Language Use and Language Teaching in Zimbabwe

[18]. Gweru: Mambo Press

[19]. Ngara, E (1985): Art and Ideology in the African Novel. London: Hernemann Educational Books. Ngugi wa Thiongo (1977): Petals of Blood Harare: Zimbabwe Publishing House Pvt Ltd.

[20]. Nando, P.J. (1996, March 16): "Dynamism of language.” Letter to the EditorThe Chronicle p.5OkaMbungwana (1996, February 22): "Abusing our Language"

[21]. Letter to the Editor The Chronicle p.5 Pride, J.B \& Holmes, J. (1972): Sociolinguistics

[22]. Middleset: Penguin BooksRiemeshneider, D. \& Schultze - Engler, E, (Ed) African Literatures in the Eighties Atlanta.

[23]. Sibanda, M (1996, February 16): "Ndebele is not Zulu"Letter to the Editor The Chronicle. 
[24]. Sigogo, N.S. (1996, March 5) : "What is this Pure Ndebele"Letter to the EditorThe Chronicle p.5 Stringer, D. (1973): Language Variation and EnglishBuckinghamshire: Open University Press The Zimbabwe Education Act (1987): Chapter 55. Harare: Government Printers

[25]. Trudgil, P. \& Anderson, L (1990) Bad Language Cambridge: Bosil Blackwell Ltd.Tunu, L.V (1996, March 2): "Ndebele is not Zulu" Letter to the Editor The Chronicle p.5Valdes - Fallis (1978): "Code - Switching among Bilingual - Metican - American women in B.L Dubois, and I Craich, (Eds) International Journal of the Sociology of Language. New York: Malton PublishersWallwork, J.F. (1978): Language and People London: Hernemann Educational Books Watson, K.H. (1987): English Teaching in Perspective: London: Open University Press

[26]. Whitely, W. H. (Ed) (1971): Language Use and Social Change. Problems of Multilingualism with special Reference to Eastern Africa London: Oxford University Press.

\section{Appendices \\ Data Presentation \\ Part A \\ Distribution Of Sample By Age}

Table 2: Teachers $\mathbf{N}=34$

\begin{tabular}{|c|c|c|}
\hline Number Of Years & $\mathbf{F}$ & $\%$ \\
\hline $15-19$ & 0 & 0 \\
\hline $20-24$ & 2 & 5,88 \\
\hline $25-29$ & 9 & 26,47 \\
\hline $30-34$ & 13 & 38,24 \\
\hline $35-39$ & 2 & 5,88 \\
\hline $40-44$ & 2 & 5,88 \\
\hline $45-49$ & 0 & 0 \\
\hline 50 And Above & 0 & 0 \\
\hline No Response & 6 & 17,65 \\
\hline
\end{tabular}

Table 3: Students: $N=208$

\begin{tabular}{|c|c|c|}
\hline Number Of Years & $\mathbf{F}$ & $\%$ \\
\hline $\begin{array}{l}15-19 \\
20-24 \\
25-29 \\
30-34 \\
\text { No Response }\end{array}$ & $\begin{array}{l}1608 \\
24 \\
3 \\
0 \\
21\end{array}$ & $\begin{array}{l}76,92 \\
11,54 \\
1,44 \\
0 \\
10,10\end{array}$ \\
\hline
\end{tabular}

Table 4: Academic Qualification Of The Teachers: N = 34

\begin{tabular}{|c|c|c|}
\hline Highest Academic Qualification S & $\mathbf{F}$ & $\%$ \\
\hline Standard 6 & 0 & 0 \\
\hline Z.J.C/Ujc & 0 & 0 \\
\hline "O" Level & 1 & 2,94 \\
\hline "A" Level & 5 & 14,71 \\
\hline B.A & 20 & 58,82 \\
\hline Bsc & 0 & 0 \\
\hline B Ed & 3 & 8,82 \\
\hline Masters Degree & 1 & 2,94 \\
\hline No Response & 4 & 11,76 \\
\hline
\end{tabular}

Table 5: Highest Professional Qualification Teachers: N=34

\begin{tabular}{|c|c|c|}
\hline Number Of Years & $\mathbf{F}$ & $\%$ \\
\hline P.T. L & 0 & 0 \\
\hline $\mathrm{T} 4$ & 0 & 0 \\
\hline Pth & 0 & 0 \\
\hline $\mathrm{T} 3$ & 2 & 5,88 \\
\hline $\mathrm{T} 2$ & 0 & 0 \\
\hline $\mathrm{Ce}$ & 6 & 17,65 \\
\hline Dip.Ed & 1 & 2,94 \\
\hline Grad.Ce & 14 & 14,18 \\
\hline No Response & 11 & 32,35 \\
\hline
\end{tabular}


Table 6: Experience As A Classroom Teacher Teachers: $N=34$

\begin{tabular}{|c|c|c|}
\hline Number Of Years & $\mathbf{F}$ & $\%$ \\
\hline $0-2$ & 6 & 17,65 \\
\hline $3-5$ & 8 & 23,53 \\
\hline $6-8$ & 8 & 23,53 \\
\hline $9-11$ & 5 & 14,71 \\
\hline $12-14$ & 2 & 5,88 \\
\hline 15 And Above & 3 & 8,82 \\
\hline No Response & 2 & 5,88 \\
\hline
\end{tabular}

Theme 1: Language As A Reflection Of Culture: Items 1, 2 And 13

Table 7: Teacher's Responses: $\mathbf{N}=34$

\begin{tabular}{|c|c|c|c|c|c|c|}
\hline \multicolumn{3}{|c|}{ Agree } & \multicolumn{2}{|c|}{ Neutral } & \multicolumn{2}{|c|}{ Disagree } \\
\hline Item & $\mathbf{F}$ & $\%$ & $\mathbf{F}$ & $\%$ & $\mathbf{F}$ & $\%$ \\
\hline 1 & 32 & 94,12 & 2 & 5,88 & 0 & 0 \\
\hline 2 & 31 & 91,18 & 1 & 2,94 & 2 & 5,88 \\
\hline 13 & 21 & 61,76 & 0 & 0 & 13 & 38,23 \\
\hline
\end{tabular}

Table 8: Students' Responsese: $N=208$

\begin{tabular}{|c|c|c|c|c|c|c|}
\hline \multicolumn{3}{|c|}{ Agree } & \multicolumn{2}{|c|}{ Neutral } & \multicolumn{2}{|c|}{ Disagree } \\
\hline Item & $\mathbf{F}$ & $\%$ & $\mathbf{F}$ & $\%$ & $\mathbf{F}$ & $\%$ \\
\hline 1 & 205 & 98,56 & 2 & 0,96 & 1 & 0,48 \\
\hline 2 & 173 & 24 & 24 & 11,54 & 11 & 5,29 \\
\hline 13 & 122 & 58,65 & 33 & 15,87 & 53 & 25,48 \\
\hline
\end{tabular}

Theme 2: $\quad$ Opinions On The Cultural Heritage Approach To Language: Items 5, 15, 17 And 22 Table 9: Teachers Responses: $N=34$

\begin{tabular}{|c|c|c|c|c|c|c|}
\hline \multicolumn{3}{|l|}{ Agree } & \multicolumn{2}{|c|}{ Neutral } & \multicolumn{2}{|c|}{ Disagree } \\
\hline Item & $\mathbf{F}$ & $\%$ & $\mathbf{F}$ & $\%$ & $\mathbf{F}$ & $\%$ \\
\hline 5 & 24 & 70,59 & 8 & 23,53 & 2 & 5,88 \\
\hline 15 & 19 & 76,47 & 0 & 0 & 8 & 23,53 \\
\hline 17 & 19 & 55,88 & 9 & 26,47 & 6 & 17,65 \\
\hline 22 & 15 & 44,12 & 13 & 38,23 & 6 & 17,65 \\
\hline
\end{tabular}

Table 10 Students Responses $\mathbf{N}=\mathbf{2 0 8}$

\begin{tabular}{|c|c|c|c|c|c|c|}
\hline \multicolumn{3}{|c|}{ Agree } & \multicolumn{2}{|c|}{ Neutral } & \multicolumn{2}{|c|}{ Disagree } \\
\hline Item & $\mathbf{F}$ & $\%$ & $\mathbf{F}$ & $\%$ & $\mathbf{F}$ & $\%$ \\
\hline 5 & 124 & 59,61 & 37 & 17,79 & 47 & 22,60 \\
\hline 15 & 146 & 79,19 & 35 & 16,83 & 27 & 12,98 \\
\hline 17 & 167 & 80,29 & 21 & 10,10 & 20 & 9,61 \\
\hline 22 & 92 & 44,23 & 69 & 33,17 & 47 & 22,60 \\
\hline
\end{tabular}


Code-Switching in Recent SiNdebele Literary works and how this relates to siNdebele ....

Theme 3: The Cultural Analysis Approach To Language: Items 6, 19, 20 And 24

Table 11: Teachers' Responses: $N=34$

\begin{tabular}{|c|c|c|c|c|c|c|}
\hline \multicolumn{3}{|c|}{ Agree } & \multicolumn{2}{|c|}{ Neutral } & \multicolumn{2}{|c|}{ Disagree } \\
\hline Item & $\mathbf{F}$ & $\%$ & $\mathbf{F}$ & $\%$ & $\mathbf{F}$ & $\%$ \\
\hline 6 & 14 & 41,17 & 5 & 14,71 & 15 & 44,12 \\
\hline 19 & 27 & 79,41 & 7 & 20,59 & 0 & 0 \\
\hline 20 & 13 & 38,23 & 9 & 26,47 & 12 & 35,30 \\
\hline 24 & 15 & 44,12 & 13 & 38,23 & 6 & 17,65 \\
\hline
\end{tabular}

Table 12: Students Responses $N=208$

\begin{tabular}{|c|c|c|c|c|c|c|}
\hline \multicolumn{3}{|l|}{ Agree } & \multicolumn{2}{|c|}{ Neutral } & \multicolumn{2}{|c|}{ Disagree } \\
\hline Item & $\mathbf{F}$ & $\%$ & $\mathbf{F}$ & $\%$ & $\mathbf{F}$ & $\%$ \\
\hline 6 & 83 & 39,90 & 26 & 12,50 & 99 & 47,60 \\
\hline 19 & 194 & 93,27 & 7 & 3,365 & 7 & 3,365 \\
\hline 20 & 37 & 17,79 & 47 & 22,60 & 124 & 59,61 \\
\hline 24 & 151 & 72,60 & 29 & 13,94 & 28 & 13,46 \\
\hline
\end{tabular}

Theme 4: Language Growth And Enrichment : Items 4, 14 And 18

Table 13: Teachers' Responses: $N=34$

\begin{tabular}{|c|c|c|c|c|c|c|}
\hline \multicolumn{3}{|c|}{ Agree } & \multicolumn{2}{|c|}{ Neutral } & \multicolumn{2}{|c|}{ Disagree } \\
\hline Item & $\mathbf{F}$ & $\%$ & $\mathbf{F}$ & $\%$ & $\mathbf{F}$ & $\%$ \\
\hline 4 & 23 & 67,74 & 6 & 17,65 & 5 & 14,71 \\
\hline 14 & 28 & 82,35 & 3 & 8,825 & 3 & 8,825 \\
\hline 18 & 20 & 58,82 & 7 & 20,59 & 7 & 20,59 \\
\hline
\end{tabular}

Table 14: Students Responses: $N=208$

\begin{tabular}{|c|c|c|c|c|c|c|}
\hline \multicolumn{3}{|c|}{ Agree } & \multicolumn{2}{|c|}{ Neutral } & \multicolumn{2}{|c|}{ Disagree } \\
\hline Item & $\mathbf{F}$ & $\%$ & $\mathbf{F}$ & $\%$ & $\mathbf{F}$ & $\%$ \\
\hline 4 & 81 & 38,94 & 25 & 12,02 & 102 & 49,04 \\
\hline 14 & 181 & 87,02 & 16 & 7,69 & 11 & 5,29 \\
\hline 18 & 106 & 50,96 & 33 & 15,87 & 69 & 33,17 \\
\hline
\end{tabular}

Theme 5: Language Decay: Items 8, 21, 23 And 25

Table 15: Teachers Responses $N=34$

\begin{tabular}{|c|c|c|c|c|c|c|}
\hline \multicolumn{3}{|l|}{ Agree } & \multicolumn{2}{|c|}{ Neutral } & \multicolumn{2}{|c|}{ Disagree } \\
\hline Item & $\mathbf{F}$ & $\%$ & $\mathbf{F}$ & $\%$ & $\mathbf{F}$ & $\%$ \\
\hline 8 & 26 & 76,47 & 3 & 8,82 & 5 & 14,71 \\
\hline 21 & 21 & 61,76 & 8 & 23,53 & 5 & 14,71 \\
\hline 23 & 16 & 47,06 & 7 & 20,59 & 11 & 32,35 \\
\hline 25 & 22 & 64,71 & 9 & 26,47 & 3 & 8,82 \\
\hline
\end{tabular}


Code-Switching in Recent SiNdebele Literary works and how this relates to siNdebele ....

Table 16: Students Responses: $N=208$

\begin{tabular}{|c|c|c|c|c|c|c|c|}
\hline \multicolumn{3}{|c|}{ Agree } & \multicolumn{2}{|c|}{ Neutral } & \multicolumn{3}{|c|}{ Disagree } \\
\hline Item & $\mathbf{F}$ & $\%$ & $\mathbf{F}$ & $\%$ & $\mathbf{F}$ & & $\%$ \\
\hline 8 & 153 & 73,56 & 27 & 12,98 & 28 & 13,46 & \\
\hline 21 & 102 & 51,92 & 50 & 24,04 & 56 & 26,92 & \\
\hline 23 & 108 & 51,92 & 54 & 25,96 & 46 & 22,12 & \\
\hline 25 & 151 & 72,60 & 29 & 13,94 & 28 & 13,46 & \\
\hline
\end{tabular}

Theme 6: Opinions On Ndebele/English Switching In Ndebele Literature: Items 7,9,10 And 16

Table 17: Teachers Responses: $N=34$

\begin{tabular}{|c|c|c|c|c|c|c|}
\hline \multicolumn{3}{|c|}{ Agree } & \multicolumn{2}{|c|}{ Neutral } & \multicolumn{2}{|c|}{ Disagree } \\
\hline Item & $\mathbf{F}$ & $\%$ & $\mathbf{F}$ & $\%$ & $\mathbf{F}$ & $\%$ \\
\hline 7 & 28 & 82,35 & 3 & 8,825 & 3 & 8,825 \\
\hline 9 & 19 & 55,88 & 5 & 14,17 & 10 & 29,41 \\
\hline 10 & 19 & 55,88 & 4 & 11,76 & 11 & 32,35 \\
\hline 16 & 13 & 38,235 & 8 & 23,53 & 13 & 38,235 \\
\hline
\end{tabular}

Table 18: Students Responses: $\mathbf{N}=\mathbf{2 0 8}$

\begin{tabular}{|c|c|c|c|c|c|c|}
\hline \multicolumn{3}{|c|}{ Agree } & \multicolumn{2}{|c|}{ Neutral } & \multicolumn{2}{|c|}{ Disagree } \\
\hline Item & $\mathbf{F}$ & $\%$ & $\mathbf{F}$ & $\%$ & $\mathbf{F}$ & $\%$ \\
\hline 7 & $185-$ & 88,942 & 17 & 8,173 & 6 & 2,885 \\
\hline 9 & 94 & 44,19 & 55 & 26,44 & 59 & 28,37 \\
\hline 10 & 108 & 51,92 & 29 & 13,94 & 17 & 34,14 \\
\hline 16 & 113 & 54,33 & 41 & 19,17 & 54 & 25,96 \\
\hline
\end{tabular}

Table 19: Teachers Responses: $N=34$

\begin{tabular}{|c|c|c|c|c|c|c|}
\hline \multicolumn{3}{|c|}{ Agree } & \multicolumn{2}{|c|}{ Neutral } & \multicolumn{2}{|c|}{ Disagree } \\
\hline Item & $\mathbf{F}$ & $\%$ & $\mathbf{F}$ & $\%$ & $\mathbf{F}$ & $\%$ \\
\hline 3 & 25 & 73,53 & 2 & 5,88 & 7 & 20,59 \\
\hline 11 & 21 & 61,76 & 7 & 20,59 & 6 & 17,65 \\
\hline 12 & 14 & 41,18 & 10 & 29,41 & 10 & 29,41 \\
\hline
\end{tabular}

Table 20: Students Responses: $\mathbf{N}=\mathbf{2 0 8}$

\begin{tabular}{|c|c|c|c|c|c|c|}
\hline \multicolumn{3}{|l|}{ Agree } & \multicolumn{2}{|c|}{ Neutral } & \multicolumn{2}{|c|}{ Disagree } \\
\hline Item & $\mathbf{F}$ & $\%$ & & $\%$ & $\mathbf{F}$ & $\%$ \\
\hline 3 & 107 & 51,44 & 38 & 18,27 & 63 & 30,29 \\
\hline 11 & 179 & 86,06 & 8 & 3,84 & 21 & 10,10 \\
\hline 12 & 75 & 36,06 & 41 & 19,71 & 92 & 44,23 \\
\hline
\end{tabular}

